\title{
Actuación y Aikido: \\ Comparaciones entre el sistema didáctico del Shu Ha Ri en las artes marciales y el sistema académico universitario en la actuación
}

Álvaro Martínez Cortés

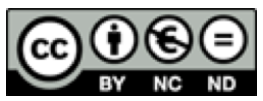

Esta obra está bajo una licencia Creative Commons

Reconocimiento-No comercial-Sin Obra Derivada 

Artículos

\title{
Actuación y Aikido: Comparaciones entre el sistema didáctico del Shu Ha Ri en las artes marciales y el sistema académico universitario en la actuación
}

\author{
Álvaro Martínez Cortés \\ Universidad Nacional de las Artes. Argentina \\ alvarojosemc@gmail.com
}

Recibido: 03 de marzo de 2016 Aprobado: 17 de noviembre de 2016

\begin{abstract}
Resumen
El presente trabajo intenta plantear algunas de las especificidades que caracterizan a la práctica de la actuación como arte teatral, para luego proponer posibles dificultades para abordar esos aspectos específicos del oficio actoral desde un programa universitario para así proponer algunas comparaciones entre la didáctica en el Aikido y la didáctica en la actuación. De esta manera, se busca señalar la posibilidad de que el entorno didáctico que se utiliza en un Dojo de artes marciales pueda ser más adecuado para el aprendizaje del arte de la actuación que el de la Universidad.
\end{abstract}

Palabras clave: didáctica, pedagogía artística, actuación, artes marciales, Aikido, enseñanza.

\begin{abstract}
The present essay seeks to lay out some of the specific aspects that characterize the practice of acting as an art, in order to propose possible difficulties that could arise when facing these specific characteristics of the craft of acting from the context of a college program, finally trying to establish comparisons between didactics in Aikido and acting. Thus attempting to point out the possibility that the learning environment promoted in a martial arts Dojo could be more adequate for the learning of the art of acting than that of a University.
\end{abstract}

Keywords: didactics, artistic pedagogy, acting, martial arts, Aikido, teaching. 


\section{Artículos}

62 ESCENA. Revista de las artes, 2016, Volumen 76, Número 1, págs. 59-84 ISSN 1409-2522 


\section{Introducción}

En el presente ensayo se intenta plantear hasta qué punto el modelo didáctico que se practica en un Dojo de artes marciales puede ser mucho más provechoso para el aprendizaje de la actuación que el que se utiliza en las escuelas universitarias de teatro.

Para enmarcar el ámbito del quehacer actoral al que se está haciendo referencia, se tomarán algunos de los planteamientos de Stanislavski (1988) sobre la acción dramática y el aprendizaje del actor. También, ha sido esencial el escrito de Luis de Tavira (2011), "Interpretar es crear", ya que sintetiza algunas de las complejidades específicas a la práctica actoral y le atribuye su dimensión estética a la posibilidad interpretativa del actor, en tanto esta es una expresión de una mirada particular sobre el objeto de trabajo: la actuación.

Por otra parte, para abordar algunas de las dificultades de la enseñanza de la actuación, se tomará como referencia las Nuevas tesis sobre Stanislavski: Fundamentos para una teoría pedagógica de Raúl Serrano (2004), así como las ideas que propone Marco Antonio de la Parra en su artículo "El cuerpo del actor", en donde se problematiza la evaluación, didáctica y transmisión de conocimientos en la enseñanza de la actuación. Un común denominador de ambos trabajos es que ambos autores coinciden en el planteo de que hay zonas del quehacer actoral que resultan difíciles de definir $y$, por ende, transmitir en la enseñanza.

Esas zonas de la actuación que no son necesariamente transferibles a través de los modelos tradicionales de enseñanza, pueden constituir parte de lo que Josette Féral (2004) plantea como zonas borrosas. La autora propone que en las metodologías analíticas que usa la semiótica puede haber un "patrón uniforme que se aplica indiferentemente tanto a la novela, a la poesía, al cine [...] y al teatro" y que, al contentarse con estudiar las "temáticas en acción en una pieza teatral", se hace omisión de "zonas borrosas y, sin embargo, fundamentales de la producción teatral, tales como el deseo, la energía, la emoción [...] el juego, la producción, la creación" (2004, pp. 20-21). Esta idea es fundacional de una nueva línea de estudios teatrales, más concentrados en los fenómenos de la práctica artística que en los resultados del objeto estético.

Es posible que sea justamente en esas zonas del oficio que Féral propone estudiar más a fondo de dónde puede surgir lo que Jorge Dubatti (2007) denomina como la especificidad del saber teatral. A partir de este concepto, Dubatti desarrolla, por medio de la frase de Mauricio Kartún "el teatro teatra", se abre la posibilidad de pensar la práctica teatral (en este caso la actuación) desde su potencial autoreflexivo. Si el arte teatral es capaz de generar conocimientos específicos a su campo desde el acontecimiento de su praxis, y estos conocimientos solo pueden ser adquiridos en tanto puedan ponerse en práctica, parece necesario poder pensar la docencia del oficio teatral, ya no solo como un proceso de transmisión de destrezas técnicas, sino más bien como una situación de aprendizaje en donde se incorporan conocimientos y saberes específicos. 


\section{Artículos}

En esa misma línea, un claro referente (desde que se decide combinar los campos de las artes marciales con la actuación), serán las investigaciones de Eugenio Barba (1997) en "Teatro, soledad, oficio y revuelta", donde elabora y define su concepto de training, permitiéndole ahondar en las dificultades de desarrollar una técnica específica y que esta pueda ser adquirida por diversos estudiantes. Las preguntas que plantea Barba respecto a la actuación como una escogencia de vida, más que como un oficio o profesión, tienen una clara influencia en la hipótesis del presente artículo (1997, p. 95).

Otro componente importante que extraemos de Barba es que su trabajo plantea un vínculo entre su práctica artística y los conocimientos que esta le ha permitido ir adquiriendo sobre el oficio del teatro. Esta capacidad reflexiva sobre su propio trabajo creativo produce ideas y conceptos sobre el teatro mismo. La posibilidad de transmitir estas ideas de forma clara las vuelve más susceptibles a ser puestas en práctica en la escena, creando además un diálogo con otros profesionales que puede marcar tendencias. Este procedimiento, en tanto "un acto entre dos o más personas comprometidas a una relación con el propósito de transmitir conocimientos o habilidades", es -como señala Festermacher (1989) - un acto pedagógico.

La relación sobre artes marciales y actuación es abordada de manera provocadora y concreta en "El actor invisible" de Yoshi Oida (1997). El actor japonés relaciona su formación tradicional de teatro en Japón, con algunas de sus experiencias en el teatro vanguardista europeo al lado de Peter Brook. Al mismo tiempo que Oida propone diversos ejercicios para abordar la enseñanza de la actuación, va relacionándolos con anécdotas y conceptos claves de las artes tradicionales japonesas, entre ellas algunas artes marciales.

De esa manera, surge la comparación entre el modelo didáctico aplicado a la enseñanza del arte marcial del Aikido con el modelo de enseñanza de actuación utilizado en las escuelas de teatro universitarias. En este punto fue de gran utilidad las nociones del Shu Ha $R i$ (modelo didáctico de las artes marciales) expuesto por el Sensei Seishiro Endo en su entrevista con Aiki magazine en el 2005.

Si pensamos, entonces, en que la actuación tiene una serie de especificidades (o saberes específicos) a los que solo se accede a través de la práctica -y que el modelo académico está mucho más orientado a la obtención de resultados que al de la exploración y el laboratorio (esenciales para la práctica actoral) - podríamos preguntarnos si no sería mejor aprender actuación bajo una línea pedagógica más cercana a la de la escuela de artes marciales (Dojo) que a la de una escuela de universitaria de teatro.

Al igual que Féral y Dubatti, la intención de este ensayo es más provocar una discusión que generar conclusiones. Es por eso que en el último apartado nos hemos propuesto anotar algunas interrogantes que puedan dar continuidad al debate. 


\section{El difícil oficio de (definir) actuar}

"Ningún otro hacer artístico participa de la identidad ser-hacer del sujeto-objeto en su realización como la que es esencial en la actuación cuando es arte." de Tavira, Luis. Interpretar es crear (2011, p. 2).

Hay una especificidad particular en el oficio actoral que lo vuelve complejo de definir y susceptible a adquirir muchas variantes que no se parecen unas a otras. Si bien está claro que actuar tiene mucho qué ver, como señala Stanislavski (1988, p. 42), con encontrar circunstancias o motivaciones que le den propósito a una acción; también queda claro que es en la interpretación de esa acción, en el modo específico en que se materializa a través del cuerpo del actor, donde yace gran parte del oficio.

La interpretación es la herramienta creativa del actor ${ }^{1}$; también, es propia a otras artes escénicas como la música y el performance. De tal modo, la dificultad de definir un entrenamiento para el actor es que este necesariamente responde a una concepción específica de la actuación.

Raúl Serrano inclusive afirma que "todo entrenamiento se encuentra [...] encaminado hacia el logro de una poética determinada" (2000, p. 78), de modo que la forma de abordar el proceso de enseñanza necesariamente tendrá que ver con la concepción del oficio actoral que se tenga. Es por esto que las metodologías de enseñanza difieren mucho entre sí, generando una gama considerable de posibilidades para el aprendizaje del arte.

Este fenómeno en sí no difiere de lo que ocurre en otras artes en las que también se pueden hallar muy diferentes formaciones; sin embargo, los resultados de estas diferencias pedagógicas son, en el teatro, más evidentes. Independientemente del estilo y técnica, la tarea de un violinista será siempre tocar el violín. Nadie se atrevería a decir que un violinista deja de serlo porque no toca música clásica.

En la actuación, en cambio, mientras que algunas formaciones ponen énfasis en la interpretación de un texto dramático, otras lo hacen sobre la capacidad emotiva del actor para enfrentar el mismo; algunas, en cambio, se concentran en las composiciones físicas de un personaje, y las hay las que ni tan siquiera consideran incluir textos dramáticos en su formación. De modo que la materia prima sobre la que trabaja el actor no es siempre la misma.

Tomando en cuenta lo anterior, a lo largo del presente ensayo se hace referencia a la actuación orientada al trabajo del actor sobre la acción y el conflicto de una pieza dramática (escrita o no), y al entrenamiento

${ }^{1}$ La importancia de la función interpretativa en el arte actoral es abordada por Luis De TAVIRA en Interpretar es crear. Reflexiones críticas sobre la diversidad conceptual del hacer del actor en el siglo XX. [En ADE Teatro. Revista de la Asociación de Directores de España. Núm. 87,2001, pp. 96-101]. 


\section{Artículos}

específico que le concierne a esta tradición del trabajo actoral ${ }^{2}$. De lo contrario - y debido a la amplia gama de concepciones que hay sobre lo que es actuar - sería imposible hablar con precisión sobre una formación, entrenamiento y enseñanza de la actuación en sus diversas variables en la extensión que pretende este artículo.

Cuando de la Parra (2011) se refiere a la actuación como un oficio imposible, podríamos inferir que no está hablando del hecho mismo de actuar - que es algo de lo que casi cualquier persona es capaz- sino de la actuación elevada a la categoría de arte. Cuando el actor va más allá del ejercicio de representar a otro y además logra dar a esa representación una forma estética, la actuación deja de ser un oficio para convertirse en arte.

Ya Stanislavski ${ }^{3}$ señalaba estas dos caras del oficio cuando argumenta que el trabajo del actor no es meramente el de presentar la parte externa de un otro, sino que también debe calzar sus propias cualidades humanas en ese otro y verter en él toda su alma; pero que "el objetivo fundamental" del arte de la actuación no es sólo la creación de la "vida interna de un espíritu humano", sino también la expresión de la misma en su "forma artística." (1946, p. 15). La actuación como práctica artística, o mejor, como quehacer estético, tiene en cuenta su naturaleza escénica y el hecho de que la escena, como representación, es la construcción de una subjetividad a través de un lenguaje. Cuando Stanislavski habla de "forma artística", está haciendo referencia a una manifestación externa de un estado interno; por eso insiste en que "un actor está bajo la obligación de vivir su papel internamente, y después darle a esta experiencia una corporeidad externa" (1946, p. 15) ${ }^{4}$. En este sentido, se entiende que el actor

Debe protegerse del esfuerzo de convocar ese instante fecundo de ser el personaje a costa o gracias a la biografía, saltando por encima de la biología, destruyendo la percepción, el registro emocional propio del momento, sin mirar al abismo saltar sobre él y dejar de ser para ser lo otro. No el otro, que ya sería bastante, sino lo otro, lo santo o lo infernal, lo ominoso o numinoso, fuera de este mundo. No hay término medio para el actor. (de la Parra, 2011, p.8)

\footnotetext{
${ }^{2}$ Para delimitar algunas de las diferentes vertientes del oficio actoral según diversas tradiciones del oficio actoral fue de gran utilidad el trabajo de tesis doctoral de Erika Rojas, Metodología de la Enseñanza de la Interpretación teatral: Algunos ejemplos.

${ }^{3}$ Dado a que trabajé con una edición en inglés de la obra de Stanislavski, las traducciones aquí ofrecidas son hechas por mí mismo. Por eso, paralelo a las citas de su obra, adjunto al pie de página la versión original correspondiente.

4 "An actor is under the obligation to live his part inwardly, and then to give his experience an external embodiment” Stanislavksi, Constantin. An Actor Prepares. Routledge, New York (1946).
} 
Esta acción de externalizar una experiencia interna, de darle cuerpo y forma a una emoción, se puede considerar un arte en tanto conlleva a una experiencia estética. En ese sentido, la estética, en términos de Ranciere, se refiere a un "modo de experiencia" a través del cual percibimos una diversidad de "experiencias sensibles" producidas dentro del tejido del arte y sus técnicas de producción (2013, p.10).

En el caso específico del arte teatral, Jorge Dubatti (2007) sostiene que el acontecimiento teatral es un convivio al cual asistimos para construir subjetividad, ser parte de una experiencia sensible e "intervenir en una zona de experiencia” (p. 17, p. 37, p. 48). Para Raúl Serrano el teatro sobre la escena "aparece como sistema y no como la mera aglutinación de sus partes" y considera que la "praxis actoral es la única que los vincula y jerarquiza” (2004, p. 70).

En consecuencia, cuando la actuación es llevada a un nivel artístico, el actor debe ser capaz, además de reconocer y afectarse con la emoción de un momento, de transmitir este reconocimiento y esta emoción, volverlas parte de sus herramientas expresivas. Aquí es donde la actuación y la emoción difieren. Stanislavski argumenta que para "expresar una delicada y vasta vida subconsciente, es necesario tener control de un aparato físico inusualmente afinado y excelentemente preparado a nivel físico y vocal" $(1946$, p. 16) Partimos entonces de que no porque una persona sea capaz de experimentar una emocionalidad intensa quiere decir que puede actuar; la actuación conlleva otro proceso más allá de la emocionalidad misma: el arte de dar cuerpo y forma a esa reacción interna y subjetiva que es la emoción. Si para esto, como señala Stanislavski, el cuerpo debe reunir una serie de requisitos, entonces el cuerpo del actor debe entrenarse. Como todo arte, la actuación requiere el dominio de una técnica.

$\mathrm{Al}$ igual que otros artistas, el actor debe entrenar su arte; así como los pintores practican sus técnicas con ejercicios de dibujo, los bailarines entrenan sus cuerpos con rutinas en la barra y los músicos desarrollan sus capacidades con ejercicios técnicos, los actores deben también mantener su cuerpo, voz e imaginación en constante entrenamiento. Sin embargo, el entrenamiento para el actor no resulta tan claro como el de otras disciplinas artísticas. A tal punto que las diversas metodologías difieren muchísimo e inclusive hay quienes consideran innecesario que un actor se entrene. La pregunta parece ser: ¿Cómo entrenar la actuación?

Planteada la pregunta de otra forma, lo que resulta esencial definir es cuál es la materia prima con la que trabaja el actor.

5 "In order to express a most delicate and largely subconscious life, it is necessary to have control of an unusually responsive, excellently prepared vocal and physical apparatus." Sanislavksi, Constantin, (1946). 


\section{Artículos}

Resulta claro que esto va a estar muy relacionado con el concepto mismo que se tenga de la actuación. En este caso, ya que se ha partido de Stanislavski para hablar de la actuación como forma artística, es preferible apegarse a la actuación en términos del trabajo del actor sobre la acción dramática de un texto. Dentro de la concepción stanislavskiana de actuación, la materia prima del actor es la acción dramática. En este marco del oficio, David Korish (2008) propone una definición del entrenamiento actoral precisa y clara que señala algunos indicios fundamentales:

El entrenamiento es ese espacio en el cual, liberado de los problemas de la performatividad, nos abocamos a los principios subyacentes de la acción dramática: su estructura rítmica, su composición física, y el entendimiento de cómo su ejecución debe incluir una relación dinámica a la ficción escénica. (2008, p. 242)

Proponemos que una característica esencial del entrenamiento actoral es que debe articularse como un espacio distinto al de la performatividad, un momento de la actuación en donde el actor trabaja en soledad y no hacia una audiencia. En ese momento se puede volcar la atención sobre los aspectos de la acción dramática que señala Korish y ponerlos a prueba en el cuerpo.

Lo anterior resulta fundamental debido a que es esencial entender que el entrenamiento es un momento diferente al ensayo y al estar en escena. El actor no entrena para montar una obra (si bien un entrenamiento particular puede después desencadenar un montaje), el actor se entrena preparando su cuerpo para la ejecución de una tarea específica -la representación de acción dramática- que después será llevada a cabo en ensayos y en la escena.

Dicho de otro modo, el entrenamiento es un espacio de preparación para la escena y no de la escena. Esta preparación tiene más que ver con la adquisición de un estado escénico y menos con la repetición mecánica de lo que será representado, o la mera formación técnica (vocal y corporal) que le permite articular su cuerpo como instrumento de su oficio.

De forma evidente, el entrenamiento actoral busca desarrollar en el cuerpo del actor sus capacidades motrices y vocales, pero no de cualquier modo, sino como elementos que se integren a su ejecución de la acción dramática; de lo contrario, bastaría con que practique canto y cualquier deporte.

Un actor puede tener gran virtuosismo en el canto y no por ello ser capaz de hablar convincentemente en escena. Esto último se encuentra más relacionado con sus habilidades para darle cuerpo - de forma literal- a las acciones que, con su rango vocal, proyección, colocación, dicción o cualquier otro aspecto técnico de la formación vocal.

Así como el futbolista puede hacer uso de muchos deportes para adquirir las destrezas y estado físico necesarios para jugar al fútbol -aunque solo el fútbol puede hacerlo entrenar las habilidades específicas que usará durante un partido-, de igual forma, el actor puede echar mano de una amplia gama 
de disciplinas para acondicionar y mejorar sus capacidades físicas (canto, esgrima, boxeo, acrobacia, artes marciales, danza, entre otras), pero solo el trabajo sobre la acción dramática y lo que ella implica en escena pueden ayudarlo a dar una función (Bartís. 1988).

Además de la dificultad de lograr encontrar una formación que le permita entrenar las especificidades propias de su oficio, el actor, muchas veces, se encuentra ante la disyuntiva de tener que aprender un oficio en condiciones de simulacro.

$\mathrm{Al}$ igual que los pilotos de avión, los actores tienen una buena dosis de instancias de simulacro en su formación. Si bien estas pueden reponer en parte lo que constituye la experiencia real de exponerse a una función ante público, jamás podrán garantizar al aspirante que se encuentra definitivamente preparado. No es solamente el problema de ser observado lo que debe preocupar al actor, sino esa dificultad añadida de que aquello que hace es irrepetible.

Luis de Tavira señala una de las características definitivas del arte actoral, y podríamos decir, que como tal, la principal diferencia con respecto a otros quehaceres artísticos:

Y si fuera posible definir alguna constante histórica en la diversidad diacrónica y sincrónica del devenir de la actoralidad, ésta sería su irrepetibilidad, su condición efímera y su incesante mutación, lo cual sólo define paradójicamente su consistencia indefinible. (2001, p. 2)
A diferencia del músico, que también puede padecer pánico escénico, el actor sólo puede saber si ha logrado obtener maestría sobre su oficio en el instante mismo que lo ejecuta ante otros. En cambio, el músico sabe que puede tocar una sinfonía completa con perfecta maestría cuando la hace sonar en su instrumento; si el pánico escénico no le permite mostrárselo al mundo, puede perfectamente grabarse, pero el dominio está ahí.

El oficio de la actuación ocurre solamente en la escena, ya que hay cuestiones de la técnica de representar una acción que solamente ocurren ante otros. Si un actor graba ante una cámara, no será lo mismo. Nada en la relación con ese lente mecánico repone la experiencia de un auditorio vivo. El momento de convivio, para citar a Dubatti (2007), de estar ante un público ejercitando su oficio, le propicia al actor el único espacio de prueba que dispone para verificar lo aprendido, así como una experiencia que puede ir revalorando con las lecciones sucesivas. Aprender a actuar solamente en el aula es imposible, siempre hacen falta las tablas.

Del mismo modo, hay partes del oficio que, además de ser complejas de poner en palabras o de atribuirles una categoría, se vuelven intransferibles. Como apunta Barba:

Hay procedimientos técnicos que pueden pasar fácilmente de uno a otro y que se dejan condensar en principios claros. En la profesión, constituyen el terreno de la objetividad. En el extremo opuesto, está el calor personal que caracteriza a cada individuo, una temperatura que le 


\section{Artículos}

pertenece, y es inimitable. O que, al imitarse, se vuelve parodia. (2010, p. 22)

La segunda instancia del oficio a la que se refiere Barba, y que tiene que ver más con la propia subjetividad de cada individuo, es a lo que - a falta de un mejor término- suele llamarse "talento". No obstante, este concepto responde a una noción más romántica de la práctica actoral que, al reducir la actuación a una cuestión de si se tiene o no un "don" intangible, de algún modo, le restan méritos al esfuerzo, trabajo, estudio y profesionalismo que esta requiere.

Contrario a la creencia popular de que el actor es un ser naturalmente dotado de una facilidad para ejercitar la actuación y que esto le permite realizar sus proezas con facilidad, el oficio actoral es complejo y requiere de gran dedicación y tiempo, además de un alto nivel de generosidad ya que siempre conlleva riesgos por la gran exposición que le exige a sus practicantes.

Pese a esto, el mito de que los actores se bastan de su talento para llevar a cabo sus tareas, persiste. El siglo veinte, a través de las experiencias de distintos maestros y sus esfuerzos por reflexionar sobre sus prácticas, va a ser el que busque desmitificar al actor como un ser inspirado por las musas, y rescatarlo como el profesional de un complicado oficio en el que puede haber rasgos particulares en la persona que le favorezcan en la práctica.

El talento es bienvenido en cualquier quehacer. Sería un error pensar que solamente en la actuación es un factor determinante en las posibilidades de éxito. La diferencia es que se le ha tomado más en cuenta en las artes que en otros oficios, pero no por esto debería pensarse que es un requisito para ejecutar con dignidad una profesión artística.

En ese sentido, el entrenamiento del actor se vuelve un espacio de combate contra los mitos sobre la profesión, una condensación de instantes reveladores que van formando un carácter y una noción propia de la profesión artística. Independientemente del estilo actoral que se practique, e inclusive de la formación que se tenga, el actor ejerce en la repetición de sus ejercicios una especie de resistencia formativa que, al mismo tiempo que lo preparan para cuando llegue el momento de la escena, le irán dando la convicción de que, a fuerza de permanencia y constancia, se ha vuelto merecedor de un lugar en el teatro.

Lo que cuenta no es el ejercicio en sí mismo -por ejemplo hacer flexiones o saltos mortales- sino la justificación que cada uno da al propio trabajo, una justificación que, aunque sea banal o difícil de explicar con palabras, es fisiológicamente perceptible, evidente para el observador. [...] El training es un test que pone a prueba las propias intenciones, por lo que se cree o se afirma, la posibilidad de superar el divorcio entre intención y realización." (Barba, pp. 92-93)

La actuación, para ser ejecutada como disciplina artística, se entrena hasta que la técnica se incorpora; es decir, se internaliza en el cuerpo. De este modo la diferencia entre actuar y ser actor reside en la incorporación 
de una técnica específica del arte actoral. Un practicante de la actuación con pretensiones artísticas serias debe entrenarse con intensidad. Para poder, como dice Barba, imprimirle ese "calor personal que caracteriza a cada individuo" a un oficio, volviéndolo "inimitable", es necesario alcanzar la capacidad de ejecutarlo con la debida maestría.

En consecuencia, lo que diferenciará a un actor amateur de un actor profesional, no es su cuota de talento o virtuosismo, sino la superación entre la intencionalidad y el acto. Este salto entre el querer hacer y el hacer, se lleva a cabo mediante el dominio de la técnica que permite enmarcar al arte actoral como experiencia sensible perteneciente al campo artístico (Rancière, 2013, p. 10). El dominio de la técnica solo se adquiere mediante un arduo entrenamiento que requiere convicción y disciplina.

\section{Saber artístico o saber académico: Algunas críticas a la enseñanza de la actuación en el entorno académico}

[...] que entiendan que el teatro es delirio, legitimar en ellos la locura, aconsejarlos que no sean tan exitosos y menos precavidos y, por supuesto, nada académicos". (de la Parra, 2007, p. 25)

La hipótesis del presente apartado es que la actuación, en tanto arte, no puede ser enseñada en las universidades. Hay una clara intención de provocación detrás de esta afirmación, y es evidente que obliga a hacerse una serie de interrogantes, de las cuales se ha decidido aplicarse a responder a dos en particular:
¿Por qué no se puede enseñar actuación, en tanto arte, en las universidades? $\mathrm{Y}$ ¿qué se enseña en las escuelas universitarias de teatro con carreras de actuación?

La primera conlleva a señalar las incompatibilidades de las condiciones y requisitos de enseñanza, dictadas por la academia, con las circunstancias que nos parecen básicas para el aprendizaje de la práctica actoral, en tanto arte.

Uno de los principales problemas que surgen en la formación actoral de las universidades es cuando el estudiante se enfrenta a la instancia de evaluación. Más allá de que en la pedagogía se cuestionan las metodologías de evaluación tradicionales, en el caso de evaluar la actuación, nos encontramos ante un problema particular, especialmente si dicha evaluación es tradicional, entiéndase en una instancia de examen con una calificación final del uno al diez. En este sentido, ¿cómo se puede evaluar un arte que, como se menciona en el apartado anterior, se define por su irrepetibilidad?

Más allá de esa problemática, ¿cómo se evalúa un objeto artístico que sólo existe en el momento en que se produce? Como señala Dubatti (2007), el acto poético del teatro vincula la acción creadora con el objeto creado $y$, por ende, el ente generado por la producción teatral es ausente "antes y después de la acción” (p. 91). Entonces, ¿qué se estaría evaluando? ¿un instante o un proceso de aprendizaje?; ¿acaso el peso de la evaluación de un proceso actoral no debería estar puesta más sobre el proceso creativo del estudiante que 


\section{Artículos}

sobre el resultado final?

La calificación de un examen de actuación, si partimos del hecho que toma una pequeña parte de un todo, debería sumar un porcentaje mínimo de la nota final de un curso. Sin embargo, en la universidad, el examen final es la prueba de mayor porcentaje con respecto a la nota.

Esto en sí ya es una importante contradicción con el oficio actoral. Si partimos del hecho de que uno de los elementos definitivos del oficio actoral es el entrenamiento, parece desmedido evaluar en demasía un examen como suma final de un proceso mucho más complejo. Si bien es cierto que el entrenamiento debería preparar al actor para la escena y que, por ende, al evaluar una escena podemos juzgar si un actor ha incorporado su entrenamiento o no; como decíamos anteriormente, el entrenamiento es una instancia desvinculada del momento escénico en sí mismo (pese a que trabaja para llegar a él), por lo que parece imposible evaluar dicho proceso a partir del resultado de un momento arbitrario.

Por otro lado, cualquier actor profesional sabe que una obra en su estreno está lejos de ser un producto final, porque una obra (o trabajo escénico) es un objeto sujeto a diversos cambios, especialmente los que provoca el paso del tiempo. Sin duda, la evaluación es uno de los aspectos más contradictorios y complejos a tomar en cuenta en el proceso de enseñanza de la actuación en la universidad. Obligadamente surge la pregunta: ¿es necesaria dicha evaluación?

Conozco maestros que no entienden la evaluación.

¿Cómo se pone nota al instante del talento?

¿Entienden todos los alumnos lo mismo?

¿Están en el mismo momento de evolución?

¿Pueden compartir el mismo curso?

¿O debería haber una sola asignatura, la única, que los reúna a todos y egresen por madurez y no por notas? (de la Parra, 2011, p. 12)

Como señala de la Parra, evaluar es tarea difícil (por no decir imposible) en la enseñanza de la actuación. Desgraciadamente la universidad, al ser una institución, se encuentra regulada por una serie de normativas que requieren que la evaluación sea hecha de una manera específica. Una nota es requerida. Evaluar, en la universidad, de algún modo quiere decir jerarquizar el saber de los estudiantes, categorizándolos de acuerdo a los menos y los más. Hacerlo de otro modo (uno más relativo y que responda mejor a las necesidades individuales de cada estudiante) implicaría cambiar la concepción jerárquica de la enseñanza universitaria; necesariamente el maestro tendría que ceder su lugar de autoridad para convertirse en docente, una figura de menos autoridad, pero, si se quiere, mayor responsabilidad.

En ese sentido, de la Parra propone una figura de maestro diferente, de la cual se desprendería necesariamente una estrategia evaluativa 
o, mejor dicho, formativa de otra naturaleza a la del profesor que catedrático:

El maestro de toda disciplina debe desaparecer dejando la sensación de haber aprendido de la generosidad y del respeto [...], como el analista, sólo puede guiar desde atrás, no puede ir delante mostrando el camino. Apenas comentar lo logrado, apenas opinar, sugerir, interpretar. (de la Parra, 2011, p. 12)

Tal figura, al menos en la formación actoral ofrecida en las universidades, es difícil de encontrar; y aunque las hubiese, el método tradicional de evaluación que la academia les exige, obliga a los docentes a plantear su relación con el estudiante desde la jerarquía de evaluador-evaluado.

Además del problema de la evaluación a la que se somete el estudiante universitario en la carrera de actuación, también existe el problema de los posibles contenidos abordados en el currículo. La academia pareciera valorar el saber enciclopédico por encima de cualquier tipo de saber subjetivo.

Sin embargo, en el teatro (si bien un conocimiento amplio de contenidos ayuda) pareciera ser que es en la reflexión de la particularidad del trabajo propio en donde reside la mayor posibilidad de aprendizaje. Si se observan los trabajos de grandes directores y formadores teatrales (Stanislavski, Meyerhold, Grotowski, Brook, Barba, Wilson, de Tavira, Kartún, Griffero, de la Parra, Sanchís Sinisterra, por nombrar algunos), es en la reflexión sobre sus propias experiencias donde reside su mayor potencial. Ninguno de los trabajos de estos creadores (si bien toman como punto de partida algunos maestros) se centra exclusivamente en el estudio académico de sus referentes, sino más bien en la elaboración de un lenguaje escénico propio.

La especificidad del teatro y sus saberes consiste en que estos son "sólo accesibles en términos teatrales", es decir, a través de la experiencia que deviene del convivio que ocurre en el acontecimiento de la representación teatral (Dubatti, 2007, p. 176).

En la universidad los contenidos son varios y bastos, obligando al estudiante a abarcar una gran cantidad de referentes. Esta idea, quizás, surge más de una noción enciclopédica del intelectual, que de la necesidad de explorar sus propias herramientas personales. En la academia, las citas de autoridad siempre son necesarias para afirmar los saberes adquiridos. Se pone más énfasis en el manejo y conocimiento del estudiante de un corpus curricular, que en sus propias elaboraciones sobre sus experiencias formativas. Al respecto Korish señala el inevitable resultado de este enfoque:

[...] nuestra principal estrategia formativa es la asimilación de pedacitos de muchos métodos diferentes sin tener oportunidad de profundizar en ninguno, la técnica de un poquito de esto, un poquito de aquello". (2007, p. 240)

Al graduarse de la carrera de actuación los estudiantes habrán logrado obtener, en el mejor de los casos, un valioso acopio de 


\section{Artículos}

referentes teatrales y una cierta exposición a diversos creadores y sus lenguajes. La pregunta es si habrán logrado desarrollar una concepción personal de su oficio que les permita seguir ejerciéndolo por cuenta propia.

Cuando el estudiante se gradúa de la universidad, queda librado a su suerte. Los espacios de entrenamiento (aspecto tan fundamental para la condición artística del actor) se ven reducidos, no solo en cuanto a disponer de un espacio físico para llevarlo a cabo, sino también en cuanto a contar con un grupo de pares que posibiliten ponerlo a prueba.

David Korish ve en esta suerte solitaria a la que queda librado el estudiante de actuación el problema de que la oportunidad de participar en un montaje se vuelve, entonces, no solo una necesidad profesional de subsistencia, sino además el único espacio formativo que les queda a los actores para seguir desarrollando su oficio:

Como la mayoría de los actores [...] son incapaces de continuar su propio trabajo sobre el entrenamiento y desarrollarse independientemente del montaje escénico, colocados en una situación de ensayo, el trabajo del director prevalece. (2007, p. 238)

Esto conlleva al problema de que para desarrollar los aspectos puntuales de la práctica actoral se necesita, como se vio anteriormente, un espacio distinto al que ofrece el montaje de una obra, ya que esta no tiene un objetivo formativo (al menos no necesariamente) sino que responde a otros propósitos para los cuales, generalmente, se parte del supuesto de que los actores ya tienen cierto dominio sobre su oficio.

Este fenómeno no afecta meramente a los estudiantes, sino también a los profesores de actuación quienes, a no ser que militen en algún grupo teatral, por lo general, también carecen de espacios formativos y de entrenamiento necesarios para su práctica.

A diferencia de la música y las artes plásticas, el teatro necesita siempre el trabajo en equipo para poder ser llevado a cabo. De modo que, aunque existen algunos aspectos del entrenamiento que pueden ser ejecutados por el actor en la soledad, al final será siempre en el núcleo de un colectivo en donde los aspectos más fundamentales del trabajo teatral pueden ser puestos a prueba.

El arte actoral, ya de por sí difícil de definir, pareciera resistirse a los esquemas que la Academia requiere para incorporarlo a su institucionalidad y darle estatus de profesión; así, de la Parra intenta (adelantando la imposibilidad de su tarea) esbozar algunos aspectos, acaso los más efímeros y difíciles de definir, del arte de la actuación y cómo ellos generan algunas dificultades al proceso de enseñanza:

Si la actuación es un oficio imposible, enseñarla no tiene modo de ser una realidad.

No se enseña el talento, apenas el dominio de esos recursos innatos.

La disciplina debe contener un sentido 


\section{Artículos}

de vida, un ejemplo, otra vez, místico.

Se entrena el éxtasis, el ir y venir hacia la locura absoluta.

El actor debe padecer una personalidad múltiple y no enloquecer en el intento. (2011, p. 11)

Por su parte, Luis de Tavira propone una definición de la actuación que problematizaría muchísimo la tarea de su enseñanza en términos académicos:

Si actuar es un misterioso modo de conjugar el verbo ser en la doble dimensión de la mímesis, es decir, entre lo que es y no es, la actuación exige ser pensada como una metafísica en acción. (de Tavira, 2011, p.2)

No se trata de ensalzar el arte de la actuación elevándolo a un lugar de misticismo, sino de comprender que, quizás por su estrecho vínculo y forma de accionar sobre un tiempo y espacio determinados, actuar resulta una práctica difícil de abarcar con éxito bajo las delimitadas normas que definen una carrera profesional universitaria.

No por eso hay que negar que la obtención de un título universitario, de algún modo, dignifique, ante una sociedad esencialmente utilitarista, el quehacer teatral. Sin embargo, habría que preguntarse a qué precio. Entonces ¿no sería mejor estudiar "una carrera de verdad" y buscar otras instancias de formación para la actuación? No se entienda con esto que se propone reducir el teatro a una práctica meramente recreativa. Simplemente habría que pensar que, si de todos modos, para el medio teatral, la habilidad sigue siendo un factor más determinante que un título, por qué no adquirir dicha habilidad en otros espacios formativos que no alberguen las problemáticas a las que conlleva la academia. La pregunta sería: ¿cuáles?

\section{La didáctica del Shu Ha Ri en las artes marciales: Una propuesta alternativa para la enseñanza de la actuación}

Cuando se estudia con un maestro, las habilidades aprendidas son solo el lenguaje del entendimiento, no el propósito. Porque se está aprendiendo algo más allá de la técnica[...] (Oida, 1997, p. 112)

Usualmente se denomina Dojo al lugar destinado al proceso de enseñanza-aprendizaje de algún arte marcial.

El Dojo significa literalmente "lugar de despertar", "lugar de entrenamiento" o "donde aprendemos a VIVIR". Cuando se entra en un Dojo se entra en la casa del Sensei, que significa "uno nacido antes que uno". Los Dojos suelen ser de ambiente y decoración muy tradicional y sencilla, al igual que la vida del Samurai. El alumno viene a la casa del Sensei a aprender su forma o camino de vida. Antiguamente era algo difícil que un Sensei aceptara a un alumno (Deshi o Montei) por el mero hecho de querer aprender el arte de la escuela (ryu), éste antes de entrar tenía que ganarse la aceptación del Sensei poniéndose a prueba, estas pruebas eran tanto psicológicas como físicas (limpieza, favores, trabajos duros...); 


\section{Artículos}

eran principalmente realizadas para conocer el carácter del futuro alumno, para forjarlo y ver tanto sus capacidades mentales como físicas, fortaleciendo al mismo tiempo el cuerpo y la moral del alumno para estar preparado para su entrenamiento marcial. Una vez que el Sensei lo aceptara (que no eran todos los casos) como alumno, tomaba el nombre de Nyumon-sha, que significa "aprendiz aceptado" ("El Dojo y el Sensei" - Material Didáctico de Organización Zanshin, Dojo Central) ${ }^{6}$

Pese a que la enseñanza y práctica de las artes marciales contemporáneas han cambiado mucho desde sus orígenes, aún conservan muchos de los rasgos de su pedagogía tradicional, principalmente, la idea del Dojo y la práctica marcial como un "lugar de despertar y entrenamiento", además de la noción de que el aprendizaje de dicha práctica potencia y beneficia a sus estudiantes a nivel integral.

Las artes marciales, de manera ideal, suelen apelar al aprendizaje integral de la comunión mente-cuerpo como forma de entrenar algo más profundo, ya sea que se le denomine "ki", espíritu, yo interno o de cualquier otro modo.

A diferencia de las tradiciones marciales occidentales y -en el caso de la actuación - las artes, la cultura oriental no suele hacer la escisión mente-cuerpo que es tan común en occidente; sino que contemplan ambas cosas como partes que se integran en una unidad, estableciendo un vínculo reciproco y especular, en tanto una responde a la otra.

Diversas formas artísticas (marciales o no) contemplan la técnica como un camino para entrenar esta noción, que luego se materializa en una práctica específica que tiene su propia artesanía. En este caso, el Aikido viene (como muchas artes marciales japonesas) del Budo:

El Budo es la vía del guerrero e involucra a todas las artes marciales japonesas. El Budo realiza una exploración a través de la experiencia directa y profunda, de la relación entre la ética, la religión y la filosofía. Su asociación con los deportes es un desarrollo muy reciente; las escrituras antiguas se interesan esencialmente por una forma particular de cultivo de la mente y una reflexión sobre la naturaleza de uno mismo: ¿quién soy yo? y ¿qué soy yo? Así, en japonés, "do" significa la vía y, por tanto, ¿cómo se puede seguir esta vía?, ¿cómo encontrarla? No es sólo aprender una técnica, menos aún es una competencia deportiva. En Budo la idea no es el competir, sino encontrar paz y maestría de sí mismo. Do, la vía, es el método, la enseñanza que te permite comprender perfectamente la naturaleza de tu propia mente y de ti mismo. ("El Dojo y el Sensei" - Material Didáctico de Organización Zanshin, Dojo Central)

Lo más parecido a esto que se conoce (o

${ }^{6}$ Las referencias que son parte de los materiales didácticos de la Organización Zanshin, no están publicadas bajo ninguna editorial. Provienen directamente, en este caso, del Sensei, Damián Ravagni (5to Dan), quien tuvo la amabilidad de facilitarme estos y otros materiales. 


\section{Artículos}

quizás que más se conoce) en el teatro occidental es el paradigma del Odin Teatret de Eugenio Barba. A partir de su particular forma de entrenar, su concepción específica del entrenamiento y, después, su re-elaboración del concepto en "training", el Odin es un referente indiscutible de formación actoral. Su modelo de trabajo es mucho más parecido a un Dojo que a una Academia, y -aunque esto pueda ser llevado a discusión- su trayectoria teatral es mucho más relevante que la de cualquier grupo universitario.

Barba propone que "El training no enseña a interpretar, a ser actor, no prepara para la creación. El training es un proceso de autodefinición, de autodisciplina que se manifiesta a través de reacciones físicas" (1997, p. 92). En ese sentido enriquece la noción más tradicional del entrenamiento como la práctica que habilita el virtuosismo de una técnica, añadiéndole, además, características de formación de un carácter determinado que es específico al oficio que ese espacio de entrenamiento pone en práctica.

El actor no solamente entrena para ser mejor profesional, sino para "autodefinirse" como actor. De modo que el espacio de entrenamiento no es solo un proceso de repetición que busca dominar una serie de procedimientos para ser ejecutados a la perfección, sino que también es un encuentro consigo mismo y una confirmación de la decisión de ejercer un oficio y, de algún modo, seguir el camino que éste implica.

La didáctica del Aikido está relacionada con el concepto de Shu Ha Ri, un método tradicional de enseñanza japonesa, basado en el aprendizaje formal y que se divide en tres etapas:

In $s h u$, we repeat the forms and discipline ourselves so that our bodies absorb the forms that our forebearers created. We remain faithful to the forms with no deviation. Next, in the stage of ha, once we have disciplined ourselves to acquire the forms and movements, we make innovations. In this process the forms may be broken and discarded. Finally, in ri, we completely depart from the forms, open the door to creative technique, and arrive in a place where we act in accordance with what our heart/mind desires, unhindered while not overstepping laws"? (Seishiro, 2005, p. 2)

Cuando Seishiro habla de formas se refiere a las katas, que son ejercicios formales que el estudiante deberá ir estudiando para aprender,

\footnotetext{
${ }^{7}$ Traduzco el fragmento: "En shu, repetimos las formas y nos disciplinamos para que nuestros cuerpos las formas que nuestros antepasados crearon. Nos mantenemos fieles a las formas sin desviación alguna. A continuación, en la etapa de ha, una vez que nos hemos disciplinado para adquirir las formas y movimientos, hacemos innovaciones. En este proceso las formas pueden ser rotas y descartadas. Finalmente, en ri, completamente nos alejamos de las formas, abriendo la puerta a la técnica creativa, y llegamos a un lugar en donde actuamos de acuerdo a lo que nuestra mente/cuerpo desea, sin obstáculos aunque sin sobrepasar las leyes.
} 


\section{Artículos}

a través de la imitación del maestro, las técnicas marciales. Al inicio la forma es simplemente una partitura física a ser repetida e incorporada en el cuerpo del estudiante; de modo que la imitación será su mejor herramienta, sin buscar darle contenido alguno a lo que irá adquiriendo.

Este sistema de aprendizaje podría ser comparado, en occidente, a la enseñanza clásica de ballet y música, en donde primero se adquiere el dominio de una forma específica y, una vez que se ha incorporado con naturalidad al cuerpo, se le puede intervenir mediante la interpretación. Esto es lo que Seishiro describe como el estado de $\mathrm{Ha}$; un momento del aprendizaje en que el estudiante debe ser capaz de desprenderse de las formas aprendidas, desestructurarlas y verter en ellas sus propios contenidos, apropiándose de ellos con completa libertad en el estado de $R i$.

En principio, podría parecer que el aprendizaje de formas es rígido y lejano a la tarea de la actuación, sin embargo, si pensamos en los artistas de la Comeddia Dell'Arte, e inclusive los mismos actores del Odin, vemos que hay otras formas de performance escénico, esencialmente vinculadas a la actuación, que operan con didácticas similares al Shu Ha Ri.

Dichas formas, al igual que el Aikido, parten del precepto de que el conocimiento se puede adquirir a través del cuerpo. La repetición constante y disciplinada de un ejercicio es un delicado proceso de construcción y deconstrucción del conocimiento adquirido, mediante la re-significación de la forma a través de sus múltiples repeticiones. Cada repetición del movimiento es, inevitablemente, diferente a la anterior, por el propio devenir del tiempo y partiendo del principio de que el sujeto se modifica con él. Tampoco se está todo el tiempo en el mismo cuerpo, y así, a medida que se intenta mantener y conservar una forma en cada repetición, lo que en realidad se está haciendo es modificándola a la vez que esta va moldeando el cuerpo, volviéndolo más apto para la tarea que ella requiere. De modo que repetir la forma es adentrarse en su significado y, a partir de ahí, resignificar mediante la transformación el propio cuerpo:

[...] as I go through more and more repetitions I start to get into a rhythm and my movement becomes more flowing. Also, I almost forget which technique I'm doing. I face my partner, and when he moves I respond naturally. In addition I become better able to see myself. I came to wonder if this is what is meant by mushin (no mind) and releasing strength. It is like being in a trance ${ }^{8}$. (Seishiro, 2005, p. 4)

\footnotetext{
8 “...a medida que voy a través de más y más repeticiones empiezo a entrar en ritmo y mis movimientos se vuelven más fluidos. Además, casi que olvido qué técnica estoy haciendo. Enfrento a mi compañero, y cuando este se mueve respondo con naturalidad. En adición a esto me vuelvo más capaz de verme a mí mismo. He llegado a preguntarme si esto es lo que se quiere decir con mushin (no mente) y liberar fuerza. Es como estar en un trance."
} 


\section{Artículos}

La noción de mushin que usa Seishiro, y que es uno de los estados de la mente en el Aikido, puede resultar de suma utilidad en la enseñanza de la actuación. Se trata de llegar a una especie de grado cero en donde la unión mente-cuerpo ocurre a tal punto que el movimiento fluye por sí mismo. No es un estado de automatismo, la repetición que se ejercita en las artes marciales y en la didáctica del Shu Ha Ri, no es como la repetición mecanizada que se usa, por ejemplo, en una rutina de gimnasio. El sentido no está puesto sobre acumular para lograr un resultado, sino en insistir hasta lograr un estado del estar en el espacio. Para el oficio actoral, la noción de lograr un estado alterado de presencia en el espacio a través del trabajo específico del cuerpo, resulta especialmente útil.

No se quiere decir con esto que el actor deba practicar Aikido. Lo que se intenta señalar es la riqueza del concepto de pedagogía utilizado en la enseñanza de este arte marcial, y su posible potencia si fuera aplicada con éxito al campo de la actuación; especialmente en contraposición a los desteñidos modelos utilitaristas de la enseñanza académica que, como se dijo anteriormente, no se plantean la instancia de aprendizaje como un proceso que integre al estudiante (como individuo subjetivo) con su oficio (como expresión/ práctica de esa individualidad).

Cabe resaltar también que hay, en el ir y venir de las repeticiones, una suerte de oleaje que se constituye como un proceso de aprendizaje que adquiere un ritmo de aprehensión del conocimiento/técnica muy particular de acuerdo a cada estudiante. La relación de cada persona con su proceso de incorporación de las formas será siempre distinta, y los aportes que hagan, desde su creatividad, a las formas también van a variar considerablemente.

En esta metodología el cuerpo es donde transcurre la mayor parte del aprendizaje. No la intelectualización de una idea específica de actuación, que luego se manifiesta en el cuerpo. El proceso de adquisición de conocimientos por repetición de formas contempla a la técnica (en tanto hacer) como una fuente de conocimiento en sí misma, y no como un simple procedimiento a seguir para el hacer. Esta idea parece vincularse estrechamente con la noción de los saberes específicos del teatro y el hecho de que sólo se accede a ellos a través del teatro. Al igual que el saber teatral deviene del teatro mismo, el saber en la enseñanza de la actuación deviene del instante del hacer, en tanto es el lugar donde empieza a ocurrir el acontecimiento teatral.

Retomando el planteo de Serano (2004) de que cada técnica conlleva necesariamente una poética específica, podemos plantear que la técnica solo puede ser aprendida a través de la imitación del cuerpo del maestro, cada técnica contiene la parte de creatividad que ese maestro ha puesto en ella.

Esa parte del maestro que habita la técnica es el conocimiento específico que el docente tiene sobre su arte, es la parte que el estudiante deberá aprender cuando logre desentrañar el sentido detrás de las formas que 


\section{Artículos}

repetirá incesantemente. Imitar al maestro es establecer un vínculo con el oficio teatral:

La enseñanza de una técnica del cuerpo mezcla permanentemente el gesto y la palabra, su ejemplo y su explicación [...]. El cuerpo del maestro es el sitio de la demostración de la experiencia. El cuerpo es la materia prima que hay que transmutar para generar un conocimiento sobre sí mismo capaz de cambiar la vida. El cuerpo del maestro de actuación está en el máximo riesgo. Va y viene y el discípulo debe aprender ese oleaje de ser y dejar de ser, de estar y dejar de estar. (de la Parra, 2011, p. 10-11)

En la academia ese "máximo riesgo" del que habla de la Parra no está. El maestro no arriesga nada porque se limita a corregir, evaluar, aprobar o reprobar y desechar al estudiante para que continúe en la banda de ensamblaje del modelo industrial del que, finalmente, proviene la academia contemporánea (Robinson, 2008).

Por otra parte, en la Universidad no hay oportunidad para repetir y repetir hasta que algo ocurra, hay una duración establecida de cursada que debe ser cumplida en tiempo y forma. Esto imposibilita el principio de aprendizaje por repetición, ya que este tiene tiempos relativos a las capacidades de cada estudiante.

En cambio, en el Dojo, estas variables son respetadas y cada quien va a su propio ritmo en un mismo grupo heterogéneo que comparte diversos niveles de profundidad en el conocimiento. En las artes marciales que siguen el modelo tradicional de enseñanza, el maestro -acaso por ese "máximo riesgo" al que expone su cuerpo- establece una relación vincular con el estudiante en la que ambos emprenden un camino en el que comparten un lenguaje. Esa lengua específica que los vinculará es la técnica que uno tratará de transmitir y el otro de aprender.

En Japón hay un dicho que dice que es mejor pasar tres años buscando a un buen profesor que tomarse la misma cantidad de tiempo haciendo ejercicios con alguno inferior [...]. Hay que encontrar al profesor adecuado [...]. Cuando se estudia con un maestro, las habilidades aprendidas son solo el lenguaje del entendimiento, no el propósito. Porque se está aprendiendo algo más allá de la técnica [...] (Oida, 2006, p. 112)

Es cierto que este tipo de pedagogía, al poner todo el peso de la enseñanza sobre la capacidad de reproducción de la técnica que tenga el maestro, le da al docente una responsabilidad y una autoridad enormes. Sin embargo, se puede argumentar, primero, que las universidades, con todo el peso que dan al mérito académico y las jerarquías catedráticas, terminan por hacer lo mismo y, segundo que, si bien el docente se convierte en la única fuente de conocimiento, lenguaje del entendimiento y lugar de aprendizaje del estudiante, este podría tener a su disposición una serie de maestros para escoger.

A diferencia de las universidades, los Dojos no pretenden adquirir un carácter de institución, pues ese lo tiene el arte en sí y la escuela específica a la que cada uno se adhiere. 


\section{Artículos}

Puede haber varios maestros, con muy distintos enfoques, en una misma escuela $y$ cada uno es libre de abrir su propio Dojo. Aunque los distintos Dojos puedan ser muy diversos, como todos responden a la misma escuela del arte marcial que practican, funcionan como múltiples unidades que están conectadas por la meta común de enseñar un arte marcial. De manera que la colaboración y el trabajo común se llevan a cabo en torno al desarrollo del arte marcial en sí. Dado que no deberían buscar crecer como instituciones individuales, los Dojos más bien buscarán que el arte marcial que enseñan crezca y se institucionalice a través de la práctica. Es decir, que se interesan por el desarrollo y difusión de la práctica que enseñan y no por su propio desarrollo y difusión a través de la enseñanza.

Para esto, una escuela de artes marciales debe ser, ante todo, un espacio en donde el entrenamiento y la enseñanza establecen una relación tan unificada que se difuminan la una en la otra; ya que el entrenamiento de la técnica es también el espacio en donde ocurre el aprendizaje del arte marcial. Lo que diferencia el entrenar del aprender es el nivel de dominio que se tenga. Sin embargo, está claro que en el entrenar -mediante la repetición y la capacidad que esta da de adquirir nuevas nociones de la prácticase llega a instancias en las que se descubre algo que no estaba o se adquiere una nueva consciencia de lo que se hace. Se aprende entrenando porque el entrenamiento es un aprendizaje, y el aprendizaje solamente llega a través del entrenamiento.
Podría plantearse entonces que quizás los actores necesitan más un espacio permanente de entrenamiento-aprendizaje que un período condensado de aprendizaje. De ser así, un Dojo de actuación parecería más acorde al desarrollo de este arte que una escuela universitaria donde se imparte la carrera de actuación.

Si los procesos de montaje se asumen como instancias de entrenamiento y se tiene la idea de que porque un actor trabaja mucho termina aprendiendo, se corre el riesgo de dejar en manos del ámbito profesional los procesos de aprendizaje que deberían ocurrir en un ámbito de enseñanza.

No negamos que se puedan extraer conocimientos de las experiencias profesionales, pero también podríamos plantear que la posibilidad de generar saberes desde el oficio requiere un dominio del mismo. En consecuencia, habría que preguntar ¿cómo aprender el dominio del oficio desde un oficio que todavía no se domina? La pregunta podría dibujar la delgada línea entre aprender haciendo y hacer sin haber aprendido.

Sin embargo, para los actores iniciantes, la carencia de espacios de entrenamiento representa la ausencia de un lugar en el que puedan poner en juego (no en práctica) los saberes aprendidos y verificar sin la presión de las exigencias del espacio profesional y del resultado final, su eficacia. Como resultado, el actor arriesgará lo mínimo cuando asuma procesos de montaje y, a su vez, estos van a tender menos a la experimentación y 


\section{Artículos}

más al resultado. Las prácticas tienden a instalarse en la suficiencia de la efectividad y los actores en formación a preocuparse más por hacer bien que por aprender bien.

Korish (2007) plantea una paradoja del proceso de aprendizaje en la actuación: "Sólo si le dedicamos mucho más tiempo al trabajo que no está diseñado para el público haremos que el trabajo que sí lo está empiece a funcionar" (p. 239). Es por esto que el entrenamiento -como espacio de aprendizaje constante, como práctica de verificación del conocimiento adquirido, como encuentro con el quehacer del otro (en la medida que se entrene en conjunto) y como lugar de resignificación de todo lo anterior-constituye una práctica fundamental para el desarrollo del oficio actoral.

Cuando Eugenio Barba (1997) plantea el concepto de training, de algún modo está planteando la actuación ya no como una profesión para ser validada a través del título que emite una institución, sino como camino de vida que se lleva a cabo a través de la permanencia y la constancia. La calidad de la producción artística que devenga de este enfoque será la materialización más contundente del arte actoral como profesión.

El teatro se reivindica a sí mismo en los escenarios y no mediante grados académicos. Los Dojos, al ser espacios destinados más a buscar la práctica y desarrollo de un arte a través de su entrenamiento en comunidad, y menos instituciones de validación y legitimación del individuo a través de una titulación específica, parecen una mejor opción para que los actores encuentren, ejerciten y aprendan/enseñen su arte que las universidades.

\section{Conclusiones}

Podemos concluir que una de las particularidades de la actuación, en tanto arte teatral, es que produce saberes específicos a partir del fenómeno del acontecimiento teatral, y es solo en el momento en que se produce dicho acontecimiento que la actuación trabaja sobre su objeto: la acción teatral. De modo que, antes y después de ese instante, el actor únicamente puede prepararse para cuando llegue el momento de trabajar con el objeto, pero no podrá trabajar directamente sobre él.

Estas características generan la dificultad de que el proceso del estudiante de actuación no puede ser calificado mediante las formas cualitativas que la academia universitaria usualmente establece. Por otra parte, si la actuación está estrechamente vinculada con el trabajo creativo, y la creatividad no puede ser enseñada, ¿cómo se elabora un programa curricular en los términos que pide la universidad? Si la adquisición de la técnica para la actuación le lleva a un estudiante más tiempo que el que dispone en la cursada semestral, ¿cómo se valora su progreso en el proceso de aprendizaje? Estas dificultades a las que se enfrenta la universidad cuando decide incorporar el oficio actoral a su lista de carreras, hacen que sea necesario plantear si será a caso el ámbito universitario el 


\section{Artículos}

mejor para aprender actuación. Por tanto, ¿qué otros modelos de formación hay disponibles? ¿Hasta qué punto tiene algún significado obtener un título universitario en una carrera artística? ¿No será acaso que la práctica artística, aunque profesional y remunerada, necesita procesos formativos que no tienen que ver con los de otras carreras profesionales?

Al plantear el modelo didáctico empleado en la enseñanza del Aikido en comparación al de la universidad y al contemplar las posibilidades de poder aplicar dicho modelo a la enseñanza de la actuación, surgen algunos planteos atendibles con respecto a la pedagogía artística. Si el arte actoral requiere de un entrenamiento permanente, y este a su vez pide un espacio de trabajo al margen del trabajo profesional escénico, ¿hasta qué punto no resulta más conveniente acudir a un Dojo de forma permanente que a una escuela universitaria por unos cuantos años? Entendiendo que el aprendizaje de una técnica determinada implica la incorporación de la idea subjetiva que el maestro transmitió al enseñarla, ¿no sería mejor entrenar mucho tiempo con un mismo maestro hasta dominar una técnica, que atravesar pequeños procesos con diversos profesores que enseñan distintas técnicas? ¿Existe un riesgo de encarar la actuación como una profesión liberal más del sistema productivo, en lugar de descubrirla como un camino personal de vida que implica una determinación diferente?

Todas estas interrogantes parecieran arrojar la necesidad de profundizar en los estudios de la pedagogía artística, los procesos de creación y las herramientas específicas de trabajo que producen el fenómeno teatral. Surge la necesidad que plantea Raúl Serrano (2004) por "reconocer que aparece un nuevo territorio en la pedagogía actoral diferente al de la técnica", ya no se trata sólo de conocer distintas formas poéticas sino trabajar sobre el "desarrollo de la capacidad creativa" del estudiante (pp. 27-28). Nótese que el autor utiliza el término desarrollo en lugar de aprendizaje, lo cual parece implicar que no se trata de enseñar sino de fomentar un espacio que permita ejercitar capacidades propias a nuestra condición individual. Queda pendiente verificar cuáles son los espacios adecuados y las herramientas didácticas más precisas para ejercitar esas capacidades.

\section{Referencias}

Barba, E. (1997). Teatro, soledad, oficio y revuelta. Buenos Aires : Catálogos.

. (2010). Quemar la Casa. Orígenes de un Director. Bilbao: Biblioteca Teatro Laboratorio, Editorial Artezblai.

Bartís, R. (2006). Cancha con Niebla. Buenos Aires: Atuel.

de la Parra, M.A. (2011). El cuerpo del actor. CELCIT Teatro: Teoría y Práctica. Buenos Aires.

de Tavira, L. (2011). Interpretar es crear. Reflexiones críticas sobre la diversidad conceptual del hacer del actor en el siglo XX. 


\section{Artículos}

Revista de la Asociación de Directores de España, 87: 96-101.

Dubatti, J. (2007). Filosofía del Teatro I. Convivio, Experiencia, Subjetividad. Buenos Aires: Atuel.

Fenstermacher, G. (1989). Tres aspectos de la filosofía de la investigación sobre la enseñanza En La investigación de la enseñanza. Enfoques, teorías y métodos. Barcelona: Paidós.

Féral, J. (2004). Teatro, teoría y práctica: más allá de las fronteras. Buenos Aires: Galerna.

Korish, D. (2007). Reflexiones sobre el estado actoral en Costa Rica. En Miradas subjetivas. La tradición del presente. San José, Costa Rica: Ediciones Perro Azul.

Oida, Y. (2006): The Invisible Actor. Methuen Drama: United Kingdom.

Rancière, J. (2013). Aisthesis. Escenas del régimen estético del arte. Manantial: Buenos Aires.

Ravagni, D. (2012). El Dojo y el Sensei. Buenos Aires: Material Didáctico de
Organización Zanshin, Dojo Central.

Robinson, K. (2008): Changing Paradigms in Education. Conferencia ofrecida en la Royal Society for encouragement of the Arts, Manufacturers and Commerce, Londres, el 16 de junio del 2008. En RSA Animate. Recuperado de http://www.thersa.org/events/rsaanimate/ animate/rsa-animate-changing-paradigms.

Rojas, E. (2011). Metodología de la Enseñanza de la Interpretación Teatral: algunos ejemplos. Tesis de doctorado no publicada, Facultad de Ciencias de la Comunicación, Universidad Rey Juan Carlos.

Seishiro, E. (2005). An Interview with Endo Seishiro Shihan. En Aiki News Magazine, No.144, Spring Edition.

Serrano, R. (2004). Nuevas tesis sobre Stanislavski: Fundamentos para una teoría pedagógica. Buenos Aires: Atuel.

Stanislavski, Constantin (1988): An Actor Prepares. Routledge, New York. 